microbial compounds. "A lot of the compounds we call antibiotics are signalling molecules," explains Davies. "They are how the bacteria communicate with each other."

Wright explains that stiff evolutionary competition among microbes results in resistance to these antibiotics, but also compounds that fight resistance. "If an organism develops an antibiotic, it has a competitive advantage in the environment, until the neighbour becomes resistant to that antibiotic. So now the original guy is out of luck, so it could evolve another antibiotic pathway or it could block resistance out there." The hope is that these resistance-blocking antibiotics could be put to use for humans.

And there are other new technologies leading to discovery. Davies men- tions next-generation gene sequencing, which allows researchers to screen enormous collections of DNA from soils. These yield gene clusters, which can be put into other host organisms. "You don't isolate antibiotics as compounds from the soil; you isolate the pathways to make them."

\section{Years to clinical use}

Researchers caution that drugs from this promising research are still years away from clinical application. "This new paper [on teixobactin] is interesting, but I don't know whether the compound is going to be any good or not," says Davies. "We don't know anything about its toxicity and its mechanism of action."

Similarly, Wright's team has recently found a fungal antibiotic that "worked really well in animals, but we have to prove that it is safe and has no off-target effects." Hundreds to thousands of potential new drugs fail for every one that succeeds, and preclinical testing can last years. "Safety standards are quite rightly very strenuous."

To develop these novel compounds, Lewis and Epstein have founded a new company, and there are other start-ups working on the pipeline for these drugs. Researchers agree that entirely new classes of drugs will eventually become available. Doctors graduating today may be able to look forward to a new armamentarium during their careers. - Carolyn Brown, Ottawa, Ont.

CMAJ 2015. DOI:10.1503/cmaj.109-4985

\title{
Malnourished patients often unacknowledged
}

$\mathrm{E}$ xperts say a basic health necessity - proper nutrition — is being largely overlooked in Canadian hospitals, with patients and the health care system paying the high price.

A study in the Jan. 26 issue of Journal of Parenteral \& Enteral Nutrition found that $45 \%$ of Canadian adults are malnourished upon admission to hospitals.

"Many of these patients never got better. They were just discharged early and still malnourished," says Bridget Davidson, executive director of the Canadian Malnutrition Task Force (CMTF), a group of interested clinicians, investigators and advocates. The study, which was authored by CMTF members, monitored 1015 patients during a three-year period. The results indicated that malnourished patients were nearly twice as likely to be readmitted within 30 days "costing the system a lot of money."

But a greater cost still, says Davidson, is the effect of malnutrition on mortality and morbidity. Malnourished patients are 6.4 times more likely to die than well-nourished patients, according to the same study. Malnutrition was also associated with a three times greater risk of complications.

The United Kingdom's National Institute for Health and Care Excellence found that screening for malnutrition was third in terms of cost-effectiveness among health care interventions, exceeded only by treating hypertension and using birth control pills, says Dr. Leah Gramlich, provincial medical advisor for Nutrition Services in Alberta Health Services. "It's a low-cost investment, with high return."

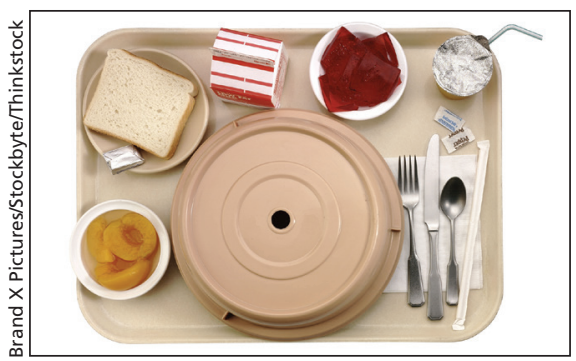

Patients who arrive in hospital malnourished may leave in a similar state because of their inability to open food packaging or reach their meals.

"Hospital malnutrition is an unacknowledged, public health crisis," she adds.

A survey of the 428 Canadian physicians working in 18 hospitals showed that most think nutrition assessment of patients is important, but it is not performed on a regular basis.

Davidson says medical school and nursing curricula do not spend enough time on nutrition, let alone malnutrition.
And those who are well educated are not being used efficiently, adds Gramlich. "Dietitians see well-nourished patients two-thirds of the time. Key nutrition people aren't spending the time with the sickest people."

One of the underlying problems in Canadian hospitals is that there are no standard methodologies to go about identifying and treating malnutrition. Counries such as the Netherlands and Britain "are far more advanced than us," says Davidson.

With screening and detection, Gramlich says staff can target malnourished patients in hospital and encourage them to eat. The Jan. 26 study showed that a third of patients in hospital ate less than $50 \%$ of the food provided to them.

Based on surveys, patients are, for the most part, satisfied with how their food tasted, said Davidson. It seemed that access to food, such as opening packages and being properly positioned to eat, was the biggest barrier.

'Let's set the patients up, protect their meal times. Let's get them to eat, so if they come in malnourished, they leave nourished." - Dane Wanniarachige, CMAJ

CMAJ 2015. DOI:10.1503/cmaj.109-4991 